\title{
Surgical antimicrobial prophylaxis among paediatric patients in South Africa comparing two healthcare settings
}

Nicolene van der Sandt, MPharm ${ }^{1}$, Natalie Schellack, PhD (Pharm) ${ }^{1}$, Lindi A Mabope, $\mathrm{PhD}(\text { Pharm })^{2}$, Mothahadini PB Mawela, MMed (Paeds) ${ }^{3}$, Danie Kruger, MSc (Pharm) ${ }^{1,4}$, *Brian Godman, $\mathrm{PhD}^{5,6,7}$

${ }^{1}$ Department of Pharmacy, Sefako Makgatho Health Sciences University, South Africa. Email: nicolene.vdsandt@gmail.com, natalie.schellack@smu.ac.za

${ }^{2}$ Department of Medicine, Sefako Makgatho Health Sciences University, South Africa. Email: lindi.zikalala@smu.ac.za

${ }^{3}$ Department of Paediatrics and Child Health, Sefako Makgatho Health Sciences

University, South Africa. Email: john.child@smu.ac.za

${ }^{3}$ Pharmacy, Private Hospital, Pretoria, South Africa. Email: Danie.Kruger@smu.ac.sa

${ }^{4}$ Strathclyde Institute of Pharmacy and Biomedical Sciences, Strathclyde University,

Glasgow, UK. Email: brian.godman@strath.ac.uk

${ }^{5}$ Division of Clinical Pharmacology, Karolinska Institute, Karolinska University Hospital Huddinge, SE-141 86, Stockholm, Sweden. Email: Brian.Godman@ki.se

${ }^{6}$ Health Economics Centre, Liverpool University Management School, Liverpool, United Kingdom. Email: Brian.Godman@liverpool.ac.uk

*Author for correspondence: Strathclyde Institute of Pharmacy and Biomedical Sciences, University of Strathclyde, Glasgow G4 0RE, United Kingdom. Email:

Brian.godman@strath.ac.uk. Telephone: 0141548 3825. Fax: 01415522562 and Division of Clinical Pharmacology, Karolinska Institute, Karolinska University Hospital Huddinge, SE-141 86, Stockholm, Sweden. Email: Brian.Godman@ki.se. Telephone + 46

858581068 . Fax +46859581070

KEYWORDS: Surgical antimicrobial prophylaxis, paediatrics, South African healthcare, compliance, guidelines.

(Accepted for publication- The Pediatric Infectious Disease Journal. Awaiting final confirmation. Please keep Confidential)

Background: Appropriate use of surgical antimicrobial prophylaxis (SAP) is a concern in view of its impact on morbidity, mortality and costs. Little is currently known about SAP in South Africa. Objective: Assess compliance to SAP guidelines for paediatric patients undergoing surgery in one of four surgical sub-specialities among hospitals in South Africa. Methods: Eight month retrospective chart review in both a teaching hospital and a private hospital between February and August 2015. Prescriptions of antimicrobials as SAP was compared to current SAP Guidelines, consolidated from a literature review, regarding 5 criteria - appropriate antimicrobial selection, dosing, timing of administration, redosing and duration of treatment. Results: 224 charts we reviewed, 112 from each hospital type. The majority $(\mathrm{p}=1.000)$ of patients received SAP when indicated $(77.3 \%$ and $100.0 \%$ respectively from the teaching and private hospital). A noteworthy $21.1 \%$ and $45.9 \%$ of patients received antimicrobials without an indication, respectively, from teaching and private hospitals. Compliance to all five of the criteria was not met by either hospital type. Overall, the teaching hospital met the most criteria (three out of five) in $58.8 \%$ of situations. Conclusion: Current SAP practices in South Africa's teaching and private hospitals diverge from current SAP Guidelines. Inappropriate overuse of SAP occurs in both hospital sectors, 
whilst underuse was found in the teaching hospital. Full compliance to the five criteria was not met by either hospital. Non-compliance was largely attributed to inappropriate selection and dosing. Quality improvement interventions, continued surveillance and local standardised evidence-based SAP Guidelines are needed to improve care. This is already happening.

\section{INTRODUCTION}

Antimicrobials are one of the most commonly prescribed medicines especially amongst paediatricians. ${ }^{1}$ However, there are concerns with increasing antimicrobial resistance (AMR) rates increasing morbidity, mortality and $\operatorname{costs}^{2}$. Consequently, there is a need to improve utilization, which includes appropriate surgical antimicrobial prophylaxis (SAP). ${ }^{3}$ This includes assessing how appropriately antimicrobials are being utilised during paediatric surgery. ${ }^{4}$ The goal for SAP is to prevent surgical site infections (SSIs), which involves administering antimicrobials that are safe, cost-effective and with a relevant spectrum of activity. ${ }^{5}$ Although half of SSIs are preventable, they remain one of the most common complications of paediatric surgery associated with significant morbidity and mortality, ${ }^{6,7}$ which can be reduced with appropriate use of SAP. ${ }^{6}$

Globally, there is substantial variability in the use of SAP, with prophylaxis amongst children accounting for $64.3 \%$ of all prophylactic antimicrobial prescribing. However, current recommendations on SAP pertain mostly to adults. ${ }^{7}$ Whilst children undergoing surgery are commonly prescribed SAP, the trend of SAP use in them is poorly understood. ${ }^{7}$ In Africa, currently more than $80 \%$ of the paediatric population undergoing surgery receive prophylactic antimicrobials; ${ }^{8}$ however, there is limited data on the appropriateness. This needs to be urgently addressed.

To date, limited research, studies and guidelines have been conducted and developed on SAP use in South Africa, ${ }^{9}$ with no comparable studies on SAP use in South Africa's paediatric surgical population. Consequently, this paper aims to describe current compliance to SAP guidelines for paediatric patients undergoing surgery in one of four surgical subspecialities following national initiatives to improve antibiotic use ${ }^{10}$. Subsequently, use the findings to guide future activities in South Africa to improve SAP in children.

\section{METHODS}

A dual approach was used including a systematic review and a retrospective review of current usage.

\section{Systematic review}

A systematic review of studies pertaining to SAP use in paediatrics undergoing surgery in one of four surgical sub-specialities, urology, Ear, Nose and Throat (ENT), maxillofacial or general surgery, was performed among 7 well know databases. All primary studies published between January 2010 and December 2016 were included. The primary outcomes had to relate to either compliance to SAP use, specific recommendations pertaining to SAP choice, timing, dosing, reducing and discontinuation or current practices of SAP use in paediatrics. The following search terms were used: Pediatric, Paediatric surgical antibiotic, antimicrobial prophylaxis, guidelines, compliance, usage, practices, patters, recommendations, urology surgery, ENT surgery, general surgery, maxillofacial surgery, with studies limited to English language. Review articles as well as those specific to the adult population (aged 18 years or older) were excluded. The principal researcher (NvdS) 
read the articles considered as relevant in entirety, and checked these with the research team to produce the final list of relevant papers (Figure 1).

Speciality-specific SAP guidelines and consensus statements were cross-referenced with key guidelines ${ }^{11-15}$ to define the most appropriate recommendations for SAP use, including dosing and type of surgical procedures (Table 1).

\section{Study design, setting and study period}

A retrospective chart review was conducted over an eight month period between January and August 2015 by studying the prescribing patterns of discharged patients requiring surgery in one of four surgical sub-speciality units, namely urology, ENT, maxillofacial or general surgery. These surgical procedures were analysed as they are the most frequently encountered in paediatrics. In addition, these were the four designated sub-specialties in the paediatric surgical ward in the teaching hospital at the time of the study.

The chosen teaching hospital is a 1,650-bed hospital with 28 clinical departments, 20 approved ICU beds, 60 high care beds and 17 surgical theatres, providing services to an estimated 1.7 million people from the surrounding area. It is the second largest hospital in South Africa. During the study period, the teaching hospital's paediatric surgical ward consisted of the four designated cubicles with a total of 40 beds.

The private hospital, reflecting the dual system in South Africa ${ }^{10}$, has 358 beds and 17 wards, two ICUs, two high care facilities and four surgical theatres. During the study period, this hospital did not have a dedicated paediatric surgical ward and children were allocated to wards based on the type of surgery that they underwent.

\section{Study population and sample}

During the eight month study period, 701 charts were reviewed; 164 from the teaching hospital and 537 from the private hospital. Thereafter 224 charts, 112 from each hospital, were sampled based on an estimation performed on Epi Info ${ }^{\mathrm{TM}}$.

\section{Compliance to the guidelines}

SAP appropriateness was evaluated with regards to indication, administration and compliance to SAP guidelines in line with previous studies following the literature review (Table 2) $)^{5,11-16}$. Compliance was defined as: appropriate selection of SAP, dose, timing of administration, re-dosing and duration of use. All five of the criteria had to be met in order for SAP to be deemed compliant in this study, i.e. SAP selected based on recommendations, appropriate doses based on body weight, SAP administered 60 minutes prior to incision apart from fluoroquinolones and vancomycin, where administration over one to two hours was recommended, potential re-dosing, and SAP administered within 24 hours post surgery

\section{Data collection and analysis}

The data collection form was developed and compiled based on previously published studies following the systematic literature review, ${ }^{4,6,7,16,17}$ with slight modifications to meet the objectives of the study. It included key information such as the type of surgery, if SAP was administered, dosage, route, time and date of administration of antibiotics.

All statistical analyses were performed on $\mathrm{SAS}{ }^{\circledR}\left(\mathrm{SAS}{ }^{\circledR}\right.$ Institute Inc, Carey, NC, USA).Fisher's exact test ( $f$ ) was used for comparisons of percentages, and the Student's t 
test $(t)$ for comparisons of mean values. All tests were two-sided and $p$-values $\leq 0.05$ were considered significant.

\section{Ethical considerations}

Data collection commenced after ethical consideration was granted from Sefako Makgatho Health Sciences University Research Ethics Committee (SMUREC) (SMUREC/H/185/2015: PG) as well as from the Research Operations Committee of the private hospital used (UNIV-2016-0013). Confidentiality and anonymity of patient information was maintained throughout the study, by means of allocating study numbers.

\section{RESULTS}

\section{Systematic review}

A total of 479,723 papers were identified through database searches, refined down to to 619 through adding additional search terms (Figure 1)

After screening for eligibility, a total of 20 final papers remained for review

Figure 1 - Outcome of the systematic review

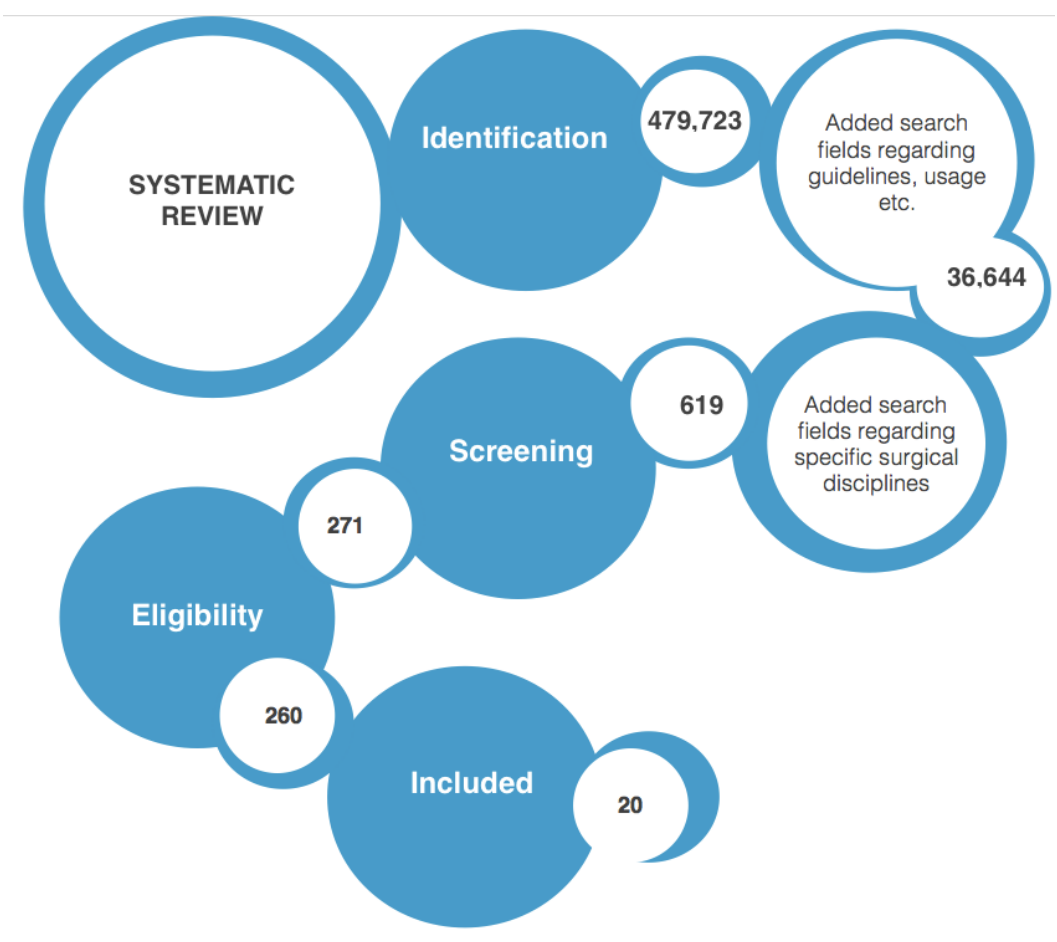

This resulted in the following criteria being develop to assess appropriate SAP among patients undergoing surgery (Table 1) 
$\underline{\text { Table } 1 \text { - Suggested antimicrobial prophylaxis among patients based on curent guidelines }}$

\begin{tabular}{|c|c|}
\hline TYPE OF SURGERY & SAP RECOMMENDATION \\
\hline \multicolumn{2}{|c|}{ EAR, NOSE AND THROAT (ENT) SURGERY } \\
\hline Tympanostomy (Grommets) & $\begin{array}{l}\text { A single dose of topical SAP is recommended. Single } \\
\text { dose of Gentisone ear drops at surgeon's discretion }{ }^{13} \text {. } \\
\text { Or a single dose of ciproflaxcain }{ }^{18}\end{array}$ \\
\hline Tonsillectomy & SAP is not recommended \\
\hline Adenoidectomy & SAP is not recommended \\
\hline \multicolumn{2}{|r|}{ GENERAL SURGERY } \\
\hline \multirow[t]{3}{*}{ Appendectomy } & SAP is highly recommended \\
\hline & $\begin{array}{l}\text { Cefoxitin or ampicillin/sulbactam or cefazolin plus } \\
\text { Metronidazole. If major reaction to beta-lactams; } \\
\text { clindamycin plus gentamycin }\end{array}$ \\
\hline & $\begin{array}{l}\text { Cefoxitin, cefotetan, cefazolin plus metronidazole } \\
\text { Clindamycin plus aminoglycosides or aztreonam or } \\
\text { fluoroquinolones }\end{array}$ \\
\hline \multirow[t]{2}{*}{ Colorectal surgery } & SAP is highly recommended \\
\hline & Gentamycin plus metronidazole \\
\hline $\begin{array}{l}\text { Hernia-repair groin (Ingui- } \\
\text { nal/femoral with or without } \\
\text { mesh) }\end{array}$ & SAP is not recommended \\
\hline $\begin{array}{l}\text { Hernia-repair groin (Laparo- } \\
\text { scopic with or without mesh) }\end{array}$ & SAP is not recommended \\
\hline $\begin{array}{l}\text { Hernia repair (Incisional with } \\
\text { or without mesh) }\end{array}$ & SAP is not recommended \\
\hline $\begin{array}{l}\text { Obstructed hernia repair (her- } \\
\text { nioplasty and herniorrhaphy) }\end{array}$ & Cefazolin, clindamycin, vancomycin \\
\hline \multicolumn{2}{|r|}{ UROLOGY SURGERY } \\
\hline Circumcision & SAP is not recommended \\
\hline & MAXILLOFACIAL \\
\hline
\end{tabular}




\section{Retrospective chart review}

\section{Demographics}

Both groups were similar in terms of weight and gender $(p<0.963$ and $p<0.591$

respectively). However, there was a statistically significant difference in terms of age $(\mathrm{p}<0.005)$ with younger patients in the private hospital. The mean age (SD, IQR) for patients in the teaching hospital was 5.45 years $( \pm 3.1, \pm 3.00-7.5)$ compared to the private hospital at 4.32 years $( \pm 2.7, \pm 2.0-6.0)$.

\section{Surgical procedures performed}

In both hospitals, the majority of patients who underwent ENT surgery were diagnosed with chronic adenotonsillitis $(30,54.6 \%$; 90, 92.8\%; for the teaching and private hospital respectively; $\mathrm{p}<0.0001)$.

In the teaching hospital in urology, the majority were diagnosed with undescended testicles (UDTs) (12 out of 33, 36.4\%) compared to redundant, prepuce phimosis and paraphimosis in the private hospital $(7,87.5 \%)(\mathrm{p}<0.0001)$. In both hospitals, all maxillofacial surgical patients $(13,100.0 \% ; 4,100.0 \%$ for the teaching and private hospital respectively) presented with dental caries $(\mathrm{p}=0.0408)$. Acute appendicitis $(5,45.5 \% ; 2,66.7 \%)$, was the main diagnosis for those who underwent general surgery respectively for both the teaching and the private hospital $\left(\mathrm{p}=0.0498^{*}\right)$. Overall, there were statistically significant difference in the total number of surgeries performed per surgical discipline between the two study populations $(\mathrm{p}<0.0001)$.

\section{Surical antimicrobial prophyaxis use}

Antimicrobials used for surgical antimicrobial prophylaxis

A statistically significant difference was seen in the antimicrobial selection for the two hospitals $(\mathrm{p}<0.0001)$ (Table 2$)$. The vast majority of patients from the teaching hospital received cefazolin, appropriately selected in one third of cases; however, under-dosed in $60.0 \%$. Further to this, $8.3 \%$ of patients received amoxicllin-clavulanic acid and one patient received cefuroxime $(2.8 \%)$. This compared to the private hospital where the vast majority of patients received amoxillin-clavulanic acid (Table 2). 
Table 2: Antimicrobials used for SAP in both hospitals

\begin{tabular}{|c|c|c|c|c|c|c|}
\hline System & Class & $\begin{array}{l}\text { ATC } \\
\text { code }\end{array}$ & INN & $\begin{array}{l}\text { Teachin } \\
\text { g } \\
\text { n }(\%)\end{array}$ & $\begin{array}{l}\text { Private } \\
\text { n (\%) }\end{array}$ & p-value ${ }^{f}$ \\
\hline $\mathrm{J}$ & \multicolumn{5}{|c|}{ Anti-infectives for systemic use } & \\
\hline J01 & \multicolumn{5}{|c|}{ Anti-bacterials for systemic use } & \\
\hline $\mathrm{J} 01 \mathrm{C}$ & \multicolumn{5}{|c|}{ Beta-lactam anti-bacterials } & \\
\hline J01CR & $\begin{array}{l}\text { Combo of } \\
\text { penicillins, } \\
\text { including beta- } \\
\text { lactamase } \\
\text { inhibitors }\end{array}$ & J01CR02 & $\begin{array}{l}\text { Amoxicillin- } \\
\text { clavulanic acid }\end{array}$ & $3(8.33)$ & $47(88.68)$ & $\begin{array}{l}<0.0001 * \\
*\end{array}$ \\
\hline J01D & \multicolumn{5}{|c|}{ Other beta-lactam anti-bacterials } & \\
\hline J01DB & $\begin{array}{l}\text { First- } \\
\text { generation } \\
\text { cephalosporin }\end{array}$ & J01DB04 & Cefazolin & $\begin{array}{l}32 \\
(88.88)\end{array}$ & $0(0)$ & $\begin{array}{l}<0.0001 * \\
*\end{array}$ \\
\hline J01DC & $\begin{array}{l}\text { Second- } \\
\text { generation } \\
\text { cephalosporin }\end{array}$ & J01DC02 & Cefuroxime & $1(2.77)$ & $1(1.89)$ & 1.0000 \\
\hline J01DD & $\begin{array}{l}\text { Third- } \\
\text { generation } \\
\text { cephalosporin }\end{array}$ & J01DD04 & Ceftriaxone & $0(0)$ & $2(3.77)$ & 0.5128 \\
\hline $\mathrm{J} 01 \mathrm{~F}$ & \multicolumn{5}{|c|}{ Macrolides, lincosamides and streptogramins } & \\
\hline J01FA & Macrolides & J01FA10 & Azithromycin & $0(0)$ & $1(1.89)$ & 1.0000 \\
\hline J01FF & Lincosamides & J01FF01 & Clindamycin & $0(0)$ & $1(1.89)$ & 1.0000 \\
\hline $\mathrm{J} 01 \mathrm{X}$ & \multicolumn{5}{|c|}{ Other antibacterials } & \\
\hline J01XD & $\begin{array}{l}\text { Imidazole } \\
\text { derivate }\end{array}$ & J01XD01 & Metronidazole & $0(0)$ & $1(1.89)$ & 1.0000 \\
\hline Total & & & & $36(100)$ & $53(100)$ & \\
\hline
\end{tabular}


NB: $\mathrm{f}=$ Fisher Exact test, ${ }^{* *}$ highly statistically significant difference.

A statistically significant difference $(\mathrm{p}=0.0399 ; \mathrm{p}=0.0130)$ was noted between the two hospitals, for both patients who did not receive any antimicrobials as SAP and those who received one antimicrobial as SAP respectively. The majority $(67.7 \%)$ of patients from the teaching hospital, and $52.7 \%$ from the private hospital, did not receive any antimicrobials as SAP. Despite being construed to a small population, more antimicrobial combination use was seen in the teaching hospital.

\section{Assessment of surgical antimicrobial prophylaxis use}

In the teaching hospital, SAP was indicated in 19.6\%; however, administered in $17.8 \%$. This compared to limited numbers in the private hospital, with a statistically significant difference seen where SAP was not indicated nor administrated (Table 3).

Table 3: Assessment of Surgical Antimicrobial Prophylaxis use

\begin{tabular}{|c|c|c|c|}
\hline Hospital & $\begin{array}{l}\text { SAP indicated } \\
n=112(100)\end{array}$ & Administered & p-value ${ }^{f}$ \\
\hline Teaching & $22(19.64)$ & 17 (77.27) & \multirow{2}{*}{1.000} \\
\hline Private & $3(2.67)$ & $3(100)$ & \\
\hline Hospital & $\begin{array}{l}\text { SAP not indicated } \\
n=112(100)\end{array}$ & Not administered & p-value $\mathrm{f}$ \\
\hline Teaching & $90(80.36)$ & $71(78.89)$ & \multirow{2}{*}{0.0003} \\
\hline Private & $109(97.32)$ & $59(54.12)$ & \\
\hline Total compliance & $88(78.57)$ & $62(55.36)$ & $0.0003 * *$ \\
\hline
\end{tabular}

NB: Abbreviations used: SAP $=$ Surgical antimicrobial prophylaxis, ${ }^{f}=$ Fischer Exact test, $* *$ highly significant

\section{Compliance to surgical antimicrobial prophylaxis}

Overall compliance to all five of the criteria (antimicrobial selection, dosing, timing of administration, redosing and duration) was not achieved in either hospital sector. $58.8 \%$ of the patients treated at the teaching hospital met three of the five criteria (Table 4).

Comparative results between the teaching and private hospitals were demonstrated for selection and dosing. Compliance in terms of timing was only met in eight patients at the teaching hospital. Full compliance to redosing and duration of treatment was achieved by both hospitals (Table 4). 
Table 4: Compliance to the five criteria

\begin{tabular}{|l|l|l|l|l|}
\hline \multicolumn{2}{|l}{ Criteria } & $\begin{array}{l}\text { Teaching n=17 } \\
(\mathbf{1 0 0})\end{array}$ & $\begin{array}{l}\text { Private n=3 } \\
(100)\end{array}$ & p-value ${ }^{\mathbf{f}}$ \\
\hline 1 & Drug selection & $5(29.41)$ & $0(0)$ & 0.5395 \\
\hline 2 & Dose & $1(5.88)$ & $0(0)$ & 1.0000 \\
\hline 3 & Timing & $8(47.06)$ & $0(0)$ & 0.2421 \\
\hline 4 & Redosing & $17(100)$ & $3(100)$ & n/a \\
\hline 5 & Discontinuation & $17(100)$ & $3(100)$ & $n / a$ \\
\hline
\end{tabular}

$\mathrm{NB}:{ }^{\mathrm{f}}=$ Fischer Exact test

\section{DISCUSSION}

Statistically significant differences were seen in the patient characteristics between the two hospitals in terms of age, primary diagnosis and the total number of surgeries performed. More elective ENT surgeries, specifically due to chronic adenotonsillitis, were performed in the private hospital, reflecting more limited access to health- and specialist care in the public system, which is now being addressed. ${ }^{10}$ As a result, adeno-/tonsillectomy has been typically reserved for patients with severe sleep disordered breathing (SDB) in the public system. ${ }^{19}$ Additionally, the burden of acute tonsillitis disease is higher compared to developed countries in view of current unemployment and poverty issues in South Africa as this is more commonly seen in paediatric patients of lower socio-economic status. ${ }^{19}$ As the teaching hospital is located in a rural area of Gauteng, other factors that may result in the variation of adeno-/tonsillectomy rates seen are the HCPs-to-population ratio and geographical access barriers. As a result, private health care patients under the age of seven years are more likely to undergo adeno-/tonsillectomies than their public health care counterparts, with HCPs feeling pressurised to accept their demands. ${ }^{19}$

The majority of patients did not receive any antimicrobials as part of SAP, with the overall use of SAP at $32.3 \%$ to $47.3 \%$ for the teaching and private hospital respectively lower than worldwide practices $(64.3 \%)^{16}$. However, when SAP was indicated, this was administered to $77.3 \%$ and $100.0 \%$ of patients from the teaching and private hospital respectively, higher than studies conducted in the USA $(72.2 \%)^{7}$. In the two categories regarding SAP use, i.e. indication and administration; no indication nor administration, the teaching hospital had the highest overall compliance (78.6\%) compared to the private hospital (55.4\%). These findings are though both lower than Italy where SAP was administered in $81.0 \%$ of cases with an indication ${ }^{16}$ and in the USA (93.8\%). ${ }^{7}$ In addition,, despite an indication for SAP, $22.7 \%$ ) of patients in the teaching hospital did not receive SAP. The inappropriate and overuse of SAP without an indication is also a concern and occurred in both hospitals, with a statistically significant difference between them $(\mathrm{p}=0.0003)$, which. exposes patients to increased risks of SSIs and/or adverse drug reactions as well as potentially increasing AMR rates. ${ }^{16}$ All of these are a cause for concern which need to be addressed. 
Specifically, ENT surgical procedures were performed for the majority of patients in both groups where SAP is not routinely recommended. ${ }^{11,13,14,18,20}$

Compliance to all five of the criteria (Table 4) was not met in either hospital sector. However, the teaching hospital complied to most criteria . This though compares well with Italy where SAP was administered appropriately in only $8.0 \%$ of cases ${ }^{16}$; similarly to the Philippines $(13.0 \%)^{21}$.

Of all patients that received SAP with an indication in the private hospital sector, none complied with current SAP guidelines with regards to appropriate antimicrobial selection. In contrast, nearly a third of all patients treated in the teaching hospital received an appropriate selected antimicrobial. These results though are much lower than similar studies in New York $(97.1 \%)^{22}$ and Singapore $(57.0 \%){ }^{6}$ again raising concerns.

An appreciable contributing modifiable driver to AMR is the appropriate selection of antimicrobials. ${ }^{23}$ Cefazolin was the SAP of choice in the majority $(88.9 \%)$ of patients in the teaching hospital in line with current guidelines, ${ }^{11-15}$; however, amoxicillin-clavulanic acid (was principally used (88.7\% of patients) in the private hospital. This is a concern as this may contribute to the emergence of AMR This may be because amoxicillin-clavulanic acid has been shown to be effective in preventing post-tonsillectomy morbidity.$^{24}$, but needs to be addressed. However, there concerns with underdosing with cefazolin in the teaching hospital that needs addressing along with

timing of administration with results worse that seen in Greece, ${ }^{25}$ Singapore $^{6}$ and the USA. ${ }^{16}$ Encouragingly though, full compliance to both redosing and duration of treatment was found in both hospitals, higher than Greece. ${ }^{25}$

\section{LIMITATIONS}

Care should be taken in the generalisation of these results across South Africa. We also accept that this study did not investigate possible causes of deviations from current guidelines including any influence of local/hospital-specific anti-biograms. In addition, we did not investigate physician knowledge, attitudes or perception to SAP. Neither did we investigate the impact of non-adherence of guidelines on morbidity, mortality and costs. Additionally, hospital charts were used for data collection with accuracy depending on the accuracy of the hospital files. However, this reflects current practice. Despite these limitations, we believe the findings are robust given the nature of the hospitals taking part, and can form the basis for future strategies to improve SAP in hospitals in South Africa in the future.

\section{CONCLUSION}

This study found substantial variation of SAP use among teaching and private hospitals, especially on SAP selection, illustrating that overall compliance to national and international SAP guidelines is sub-optimal. One possible explanation for the variation in SAP use is the lack of paediatric-specific SAP guidelines, both internationally and in South Africa. .

SAP practices did diverge from current guidelines, with inappropriate overuse of SAP occurring in both sectors, whilst underuse was limited to the teaching hospital. Full compliance to the five agreed criteria was not met though by either hospital, and there were concerns with the high inappropriate use of amoxycillin- clavulanic acid in the private hospital. 
The importance of proper use of SAP cannot be over-emphasised.. Areas for concern have been identified and quality improvement interventions including potential indicators, continued surveillance, and local standardised paediatric SAP guidelines in South Africa, are needed. . We believe this paper can serve as a blueprint or methodology for future studies in similar circumstances to develop future pragmatic quality indicators. We have started to make progress on these issues and will be reporting on our findings in the future

\section{REFERENCES}

1. De Luca M, Donà D, Montagnani $C$ et al. Antibiotic Prescriptions and Prophylaxis in Italian Children. Is It Time to Change? PLOS ONE 2016; 11(5): e0154662.

2. O'Neill J. Tackling drug-resistant infections globally: final report and recommendations. 2016. [online] amr.review.org. Available at: https://amr-review.org/sites/default/files/160525_Final\%20paper_with\%20cover.pdf

3. Romano J. Stimulus for change: Result of standardization of antimicrobial prophylaxis duration in pediatric cardiac surgery. The Journal of Thoracic and Cardiovascular Surgery 2016; 152(4): 1121-1122.

4. Sviestina I, Mozgis J, Mozgis D. Analysis of antibiotic surgical prophylaxis in hospitalized children suffering upper and lower extremity injuries. International Journal of Clinical Pharmacy 2016; 38(2): 233-237.

5. Anderson D, Sexton D. Antimicrobial prophylaxis for prevention of surgical site infection in adults 2016. [online] Uptodate.com. Available at: https://www.uptodate.com/contents/antimicrobial-prophylaxis-for-prevention-of-surgical-site-infection-in-adults

6. So J, Aleem I, Tsang D et al. Increasing compliance with an antibiotic prophylaxis guideline to prevent pediatric surgical site infection. Annals of Surgery 2015; 262(2): 403-408.

7. Sandora T, Fung M, Melvin P et al. National Variability and Appropriateness of Surgical Antibiotic Prophylaxis in US Children's Hospitals. JAMA Pediatrics 2016; 170(6): 570.

8. Versporten, A., Bielicki, J., Drapier, N., Sharland, M., Goossens, H., Najdenov, P., Čižman, M. and Unuk, S. (2016). The worldwide antibiotic resistance and prescribing in European children (ARPEC) point prevalence survey. Journal of Antimicrobial Chemotherapy, pp.1106-1117 
9. Southern African Journal of Epidemiology and Infection. 2016. 5th FIDSSA Congress 2013. [online] Available at: http://dx.doi.org/10.1080/10158782.2013.11441546

10. Meyer JC, Schellack N, Stokes J et al. Ongoing initiatives to improve the quality and efficiency of medicine use within the public healthcare system in South Africa; a preliminary study. Front Pharmacol. 2017 Nov 9;8:75

11. ASHP. Clinical Practice Guidelines for Antimicrobial Prophylaxis in Surgery 2013. [online] Available at: http://www.ashp.org/DocLibrary/BestPractices/TGSurgery.aspx

12. Choc Children's. Antibiotic Prophylaxis for Surgery Guideline 2010. [online] Available at: http://www.choc.org/userfiles/AntibioticProphylaxisFor SurgeryGuideline.pdf

13. RHSC recommendations for antibiotic prophylaxis in paediatric surgery 2016. [online] Available at: http://www.clinicalguidelines.scot.nhs.uk/media/2105/antibiotic-prophylaxis-paediatric-surgery.pdf

14. SIGN. Antibiotic prophylaxis in surgery 2014. [online] Available at: http://www.sign.ac.uk/pdf/sign104.pdf

15. The National Department of Health. (2013). Standard treatment guidelines and essential medicines list, for SA, Hospital level, Paediatrics. [online] Available at: http://passthrough.fw-notify.net/download/326174/http://www.kznhealth.gov.za/ pharmacy/PaedsSTG2013LR.pdf

16. Ciofi Degli Atti M, Spila Alegiani S, Raschetti R et al. Surgical antibiotic prophylaxis in children: adherence to indication, choice of agent, timing, and duration. European Journal of Clinical Pharmacology 2015; 71(4): 483-488.

17. Khoshbin A, So J, Aleem I et al. Antibiotic Prophylaxis to Prevent Surgical Site Infections in Children. Annals of Surgery 2015; 262(2): 397-402.

18. NHS. Paediatric Antibiotic Surgical Prophylaxis \& Perioperative Guideline. [online] Available at: http://www.nhstaysideadtc.scot.nhs.uk/Antibiotic\%20site/pdf\%20docs/Paeds\%20Surgical\%20Proph\%20final.pdf

19. Douglas-Jones $\mathrm{P}$, Fagan J. Tonsillectomy rates in the South African private healthcare sector. South African Medical Journal 2016; 106(11):1134. 
20. ASHP therapeutic guidelines - Clinical Practice Guidelines for Antimicrobial Prophylaxis in Surgery. Available at URL: https://www.ashp.org/-/media/assets/policy-guidelines/docs/therapeutic-guidelines-antimicrobial-prophylaxis-surgery.pdf

21. Nabor M, Buckley B, Lapitan M. Compliance with international guidelines on antibiotic prophylaxis for elective surgeries at a tertiary-level hospital in the Philippines. Healthcare infection 2015; 20(3-4):145-151

22. Carmeli I, Feigin E, Freud E et al. Compliance with Surgical Antibiotic Prophylaxis Guidelines in Pediatric Surgery. Eur J Ped Surg 2014; 25(02): 199-202.

23. Holmes A, Moore L, Sundsfjord A et al. Understanding the mechanisms and drivers of antimicrobial resistance. The Lancet 2016; 387(10014): 176-187.

24. Piltcher O, Scarton F. Antibiotic use in tonsillectomies: therapeutic or prophylactic? Required or excessive? Brazilian Journal of Otorhinolaryngology 2005; 71(5): 686690.

25. Dimopoulou A, Kourlaba G, Psarris A et al. Perioperative antimicrobial prophylaxis in pediatric patients in Greece: Compliance with guidelines and impact of an educational intervention. Journal of Pediatric Surgery 2016; 51(8):1307-1311. 